\title{
Single incision laparoscopic appendectomy: A prospective study
}

\author{
Nilesh P Mangam \\ Associate Professor, Department of Surgery, Government Medical College, Chandrapur, Maharashtra, India
}

Background: Appendicitis is one of the common pathologies encountered in surgical practice. Except in minority of the cases, the treatment is usually surgical. Till recent past, open appendectomy has been the procedure of choice for appendicitis. With increasing expertise in laparoscopic surgeries more and more surgeons are utilizing the laparoscopic approach for appendectomy. Laparoscopic surgeries have distinct advantages such as less surgical trauma, improved and quick postoperative recovery, and esthetic results. Single-incision laparoscopic surgery (SILS) is rapidly gaining acceptability in young population because of its cosmetic advantages. Moreover, these surgeries also avoid the risk of port-site hernias and the possibility of wound infection. Aims and Objective: The purpose of this study is to present our initial experience with this surgery using a single incision laparoscopic appendectomy (LA) using conventional instruments. Materials and Methods: This was a prospective cohort study conducted in the department of surgery of a tertiary care medical college situated in an urban area. The duration of the study was 2 years. All adult patients diagnosed to be having uncomplicated appendicitis and undergoing appendectomy by SILS were included in this study on the basis of a predefined inclusion and exclusion criteria. Pre-operative data collected included age, sex, weight, duration of complaint, concomitant medical conditions (like ischemic heart disease, chronic obstructive airway disease, diabetes mellitus, pancreatitis, and liver cirrhosis) and previous upper or lower abdominal surgery. All patients were treated by SILS except 1 patient in whom the procedure was converted to open surgery. Mean surgical time, Intraoperative procedure details and postoperative complications were studied in all the cases. $p<0.05$ was taken as statistically significant. Statistical analysis was done using SSPS 21.0 software. Results: Out of 30 patients in this study 26 patients were female and 4 patients were male. The male to female ratio was found to be 1:6.15. Mean age of studied cases was found to be 26.2 years. Operative time required for the first 15 cases in an average was 120.00 min however it was reduced for the next 15 cases was 73.73 min. Overall time required in an average was $96.86 \mathrm{~min}$. Out of 30 cases, The procedure was completed with Single Incision LA in 23 Patients, i.e., $76.6 \%$. In the initial cases, we started with two $5 \mathrm{~mm}$ and one $10 \mathrm{~mm}$ port. To reduce crowding we replaced the $5 \mathrm{~mm}$ port to $3 \mathrm{~mm}$ port. The $10 \mathrm{~mm}$ port was also replaced by $5 \mathrm{~mm}$ in the past few cases in 1 patient the procedure was converted to open surgery. The analysis of postoperative complications showed that five patients had Post-Operative wound Infection. One patient had post-operative peritonitis. Conclusion: SILS is a feasible and safe surgical method for appendectomy and is being increasingly preferred particularly by young patients due to its excellent cosmetic results.

Key words: Single-incision laparoscopic surgery; Acute appendicitis; Appendectomy; Cosmetic results

\section{INTRODUCTION}

Appendicitis is one of the common causes for which surgical consultations are sought. It usually presents with

\section{Access this article online}

\section{Website:}

http://nepjol.info/index.php/AJMS DOI: $10.3126 / a j m s . v 12 i 12.39226$

E-ISSN: 2091-0576

P-ISSN: 2467-9100

Copyright (c) 2021 Asian Journal of Medical Sciences

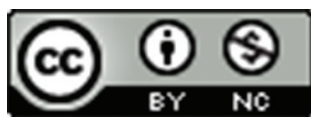

This work is licensed under a Creative Commons Attribution-NonCommercial 4.0 International License. 
be diagnosed by ultrasound examination which is a quick and reliable imaging technique. ${ }^{2}$ In some cases where the diagnosis can't be established or ruled out on the basis of ultrasound a computerized tomography may be required for diagnosis. ${ }^{3}$ It is also useful for diagnosis in pediatric patients in whom it's difficult to demonstrate inflamed appendix particularly in children who remain non-cooperative during ultrasound scanning. ${ }^{4}$

Once the diagnosis is established management is usually surgical and appendectomy has been the surgical procedure of choice once the diagnosis is established. ${ }^{5}$ Till recent past Open appendectomy has been the procedure of choice for appendicitis. With increasing expertise in laparoscopic surgeries more and more surgeons are utilizing the laparoscopic approach for appendectomy. ${ }^{6}$ Laparoscopic surgeries have distinct advantages such as less surgical trauma, improved and quick postoperative recovery, and aesthetic results. Following laparoscopic appendectomy (LA), the patient is able to quickly return to performing everyday activities and there is a significant reduction in hospital stay following surgery as compared to patients who have undergone appendectomy by open surgery. ${ }^{7}$

Minimally invasive surgical approaches used for appendectomy include traditional LA, Single-incision laparoscopic surgery (SILS), natural orifice transluminal endoscopic surgery (NOTES), and mini laparoscopyassisted natural orifice surgery (MANOS) ${ }^{8}$ In conventional LA usually 3 incisions are taken whereas in SILS, as name suggests, only 1 incision is used to perform appendectomy. SILS is usually done by single transumbilical incision. Relatively newer techniques such as NOTES and minilaparoscopy-assisted natural orifice surgery (MANOS) utilizes natural orifices such as vagina to perform appendectomy in an effort to avoid any visible scar. ${ }^{9}$ It also does have advantages such as reduced surgical pain, reduced analgesic requirement, faster recovery, absence of risk of hernia formation, and reduced risk of surgical site infection. ${ }^{10}$

SILS is rapidly gaining acceptability in young population because of its cosmetic advantages. Moreover, these surgeries also avoid risk of port-site hernias and the possibility of wound infection. In expert hands, the scar is practically hidden within the umbilicus leaving no visible scar mark of surgery. Although SILS has many advantages it definitely is a more challenging procedure as compared to open or even conventional LA. Moreover, the duration of surgery for SILS is longer as compared to conventional laparoscopic surgery and this needs to be carefully considered while selecting patients for SILS. Moreover, single incision surgery provides a compromised view and locomotive field for surgeon which is one of the biggest challenges for surgeons. ${ }^{11}$

The purpose of this study is to present our initial experience with this surgery using a single incision LA using conventional instruments.

\section{Aims and objectives}

The aim of this study was to present a minimally invasive technique for appendectomy and to study the complications in patients undergoing single incision laparoscopic appendectomy (LA) using conventional instruments.

\section{MATERIALS AND METHODS}

This was a prospective cohort study conducted in the department of surgery of a tertiary care medical college situated in an urban area. The duration of the study was 2 years. All adult patients diagnosed to be having uncomplicated appendicitis and undergoing emergency as well as elective appendectomy by SILS were included in this study on the basis of a predefined inclusion and exclusion criteria. The institutional ethical committee approved the study and written informed consent was obtained from all the patients.

The study participants were interviewed and examined according to the preformed and pretested proforma and then operated as per the defined procedure. Preoperative data collected included age, sex, weight, duration of complaint, concomitant medical conditions (such as ischemic heart disease, chronic obstructive airway disease, diabetes mellitus, pancreatitis, liver cirrhosis), and previous upper or lower abdominal surgery. Routine laboratory investigations such as complete blood count, liver function tests, blood sugar, blood urea, and serum creatinine were done in all the cases. The diagnosis was made on the basis of history and clinical examination. The diagnosis was confirmed by ultrasound examination. In cases where there was significant probe tenderness and radiologist could not find inflamed appendix on ultrasound a computerized tomography was done for confirmation of diagnosis.

Appendectomy done was either emergency appendectomy or elective appendectomy. Patients in whom elective appendectomy was done Patients were managed by Oschner Sherren regime consisting of indoor management including intravenous antibiotics, intravenous fluids, nil oral status, and frequent clinical examination to rule out spreading peritonitis, which is an indication for abandoning the conservative treatment. In these cases, SILS appendectomy was done after 6 weeks. If converted 
to conventional laparoscopic/open method, the causes of conversion, step at which converted, time after which conversion was done and the number of additional ports used were noted.

\section{Surgical procedure}

All patients were administered general anesthesia and were given supine position. A prophylactic dose of antibiotics (ciprofloxacin $200 \mathrm{mg}$ and metronidazole $500 \mathrm{mg}$ iv) was given at induction. The operating surgeon stood on the left side of the patient along with the assistant. A vertical incision around $1.5-2 \mathrm{~cm}$ was made through the umbilicus, Incision was deepened and the peritoneum was opened under direct vision (Hasson technique). A $10 \mathrm{~mm}$ port was introduced. CO2 insufflation was done and pneumoperitoneum was created $(12-14 \mathrm{~mm} \mathrm{hg})$. A rightsided $5 \mathrm{~mm}$ and left-sided $3 \mathrm{~mm}$ working ports were introduced through the same incision on either side of the optical port (Mickey Mouse Technique). Ports were placed at different levels to maximize the working space and instrument range of motion within the peritoneal cavity. Table was placed in Trendelenburg position with left-sided tilt.

Mesoappendix was then cauterized using bipolar cautery. Two roeders knot was applied at the base of the appendix and one above it and the appendix was cut in between $2^{\text {nd }}$ and $3^{\text {rd }}$ roeders knots. Lateral peritoneal dissection with caecal mobilization was done in case of non-visualization of the appendix. The appendicular base was dissected first in case of non-visualization of the appendicular tip in some cases. Epidural needle was inserted in the right iliac fossa and prolene loop was made and inserted to suspend the appendix (Puppeteer technique) when required. The appendix was removed from the $10 \mathrm{~mm}$ port after hemostasis was confirmed. Suction and Irrigation were done when required to clear the remaining debris and collection.

Ports were removed, subcutaneous layer closed with port closure vicryl and Skin closed with nylon 3-0. All port sites were infiltrated with $2 \mathrm{cc}$ of $0.25 \%$ Bupivacaine, just before closure of port sites. All patients received an intraoperative dose of $75 \mathrm{mg}$ Diclofenac. Cleaning and dressing were done.

Patients were kept nil by mouth until evening and were supplemented by intravenous fluids. Oral was allowed by evening unless contraindicated. Post-operative pain was measured using 0-10 Numerical Pain Rating Scale as described by Pasero. ${ }^{12}$ The pain scale involved asking the patient to estimate their pain severity as a number " 0 " being no pain and " 10 " being worst possible pain at postoperative time of $6 \mathrm{~h}$.
All patients received injectable Diclofenac $75 \mathrm{mg}$ postoperatively once at $8 \mathrm{~h}$ until the patients were allowed orally then oral diclofenac $50 \mathrm{mg}$ for 3 days in bid dosage. Patient was discharged when he/she was suitable for discharge, which was evaluated clinically. Post-operative hospital stay was calculated in days.

Post-operative check dressing was done on day 3. Suture removal was done on day 7. Patients were followed up until 2 months with a regular OPD checkup once in 15 days. Patients were then assessed for post-operative complications like intra-abdominal collection, peritonitis, wound infection, seroma formation, wound gape, scar pain, scar hypertrophy, port site hernia, and any mortality if any. Statistical analysis was done using SSPS 21.0 software.

\section{Inclusion criteria}

1. All adult patients diagnosed to be having uncomplicated appendicitis and undergoing emergency as well as elective appendectomy by SILS

2. Those who gave informed written consent to be part of the study.

\section{Exclusion criteria}

1. Those who refused consent

2. Age less than 18 years

3. Appendicular perforation or abscess

4. Patients on analgesics for chronic pain likely to hinder assessment of postoperative pain.

\section{RESULTS}

This study was carried out in the Department of Surgery, of our institute. In this study, 30 patients of appendicitis were treated by Single Incision LA. Of 30 patients in this study, 26 patients were female and four patients were male. The male-to-female ratio was found to be 1:6.15 (Figure 1).

Most of the patients undergoing Single Incision LA were in the age group 30-39 years (33.33\%), followed by 20-29year age group (30\%) and 10-19 age group (30\%) each. The mean age of studied cases was found to be 26.2 years (Table 1). Single Incision LA was performed for Acute Appendicitis in two patients. Interval Appendectomy was performed in 28 patients (Table 1).

\begin{tabular}{|c|c|c|}
\hline Age in years & No of Patients & Percentage \\
\hline $10-19$ & 9 & 30 \\
\hline $20-29$ & 9 & 30 \\
\hline $30-39$ & 10 & 33.33 \\
\hline$>39$ & 2 & 6.67 \\
\hline
\end{tabular}


Operative time required for the first 15 cases in an average was $120.00 \mathrm{~min}$ however it was reduced for the next 15 cases was $73.73 \mathrm{~min}$. The overall time required in an average was $96.86 \mathrm{~min}$. The minimum time required to perform SILS was $40 \mathrm{~min}$ and the maximum time was $175 \mathrm{~min}$ (Table 2).

Of 30 cases, 16 cases were completed using Single-incision with 3 ports. In six cases a prolene loop was inserted with the help of an epidural needle in the right iliac fossa to suspend the appendix. In one case a $2 \mathrm{~mm}$ alligator grasper was used through the suprapubic region to suspend the appendix. In six cases an additional $5 \mathrm{~mm} / 3 \mathrm{~mm}$ port was used during the procedure. In one case single incision LA was converted to open appendectomy due to nonvisualization of the appendix. Of 30 cases, the procedure was completed with single-incision LA in 23 patients, i.e., $76.6 \%$. In the initial cases, we started with two $5 \mathrm{~mm}$ and one $10 \mathrm{~mm}$ port. To reduce crowding we replaced the $5 \mathrm{~mm}$ port to $3 \mathrm{~mm}$ port. The $10 \mathrm{~mm}$ port was also replaced by $5 \mathrm{~mm}$ in the past few cases. The $10 \mathrm{~mm}$ just being finally used only for retrieval. This solved the problem of crowding at the umbilicus. However, it was observed that it was difficult to hold a turgid appendix with $3 \mathrm{~mm}$ instrument. In cases where an initial $10 \mathrm{~mm}$ port was used for dissection Appendix was retrieved from the $10 \mathrm{~mm}$ port. In cases where $10 \mathrm{~mm}$ port was not used to begin with, one $5 \mathrm{~mm}$ port was replaced by $10 \mathrm{~mm}$ port at the end, and an appendix was retrieved from this port. We used in couple of cases, a technique where the long end of vicryl of $3^{\text {rd }}$ roeders knot stays out of $5 \mathrm{~mm}$ port and a thread was passed through $10 \mathrm{~mm}$ port blindly and the free end of the thread is railroaded through the $5 \mathrm{~mm}$ port and tied and bought out of $10 \mathrm{~mm}$ port hence the specimen can be brought out from $10 \mathrm{~mm}$ port. This obviated the need of $5 \mathrm{~mm}$ telescope. In 16 cases appendix was retrocaecal and hence lateral peritoneal dissection with caecal mobilization was done in these cases. In the remaining 14 cases inflamed appendix could be approached without caecal mobilization. Meso appendix was dissected with bipolar cautery in most cases $0.10 \mathrm{~mm}$ and $5 \mathrm{~mm}$ clips were used in few cases. Harmonic Scalpel was used in one case (Figure 2 and Table 3).

Of 30 cases, five patients had post-operative wound infection. One patient had post-operative Peritonitis for which re-exploration was done on post-operative day 2 and peritoneal suction and irrigation was done (Table 4).

\section{Table 2: Operative time in studied cases}

\begin{tabular}{lc}
\hline No of cases & Time in minutes \\
\hline In first 15 cases & 120.00 \\
In next 15 cases & 73.73 \\
Overall average time in 30 cases & 96.86 \\
\hline
\end{tabular}

Out of 30 patients, 18 patients were discharged on day 2 which accounts for $60 \%$ of total patients. Nine patients were discharged on day 3 , whreas 2 patients were discharged on day 4. One patient was discharged on day 14. The mean average of hospital stay is 2.83 days (Table 5).

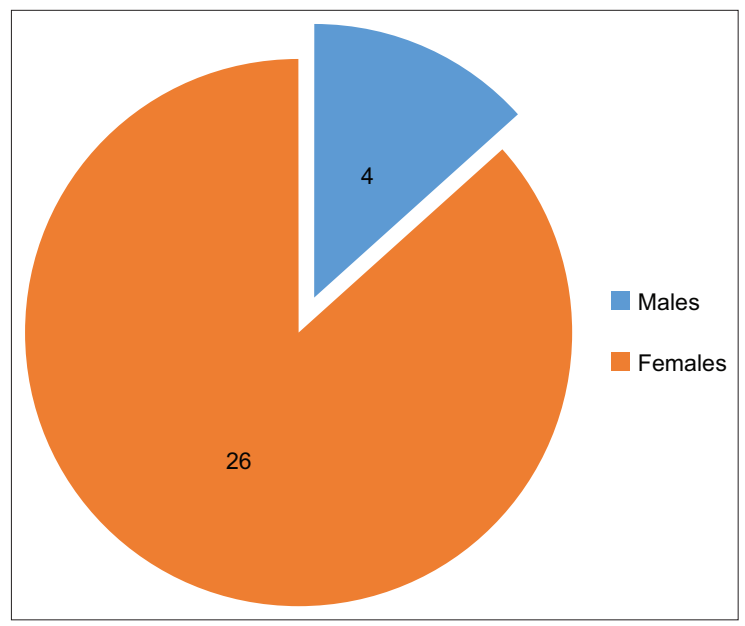

Figure 1: Gender distribution of studied cases

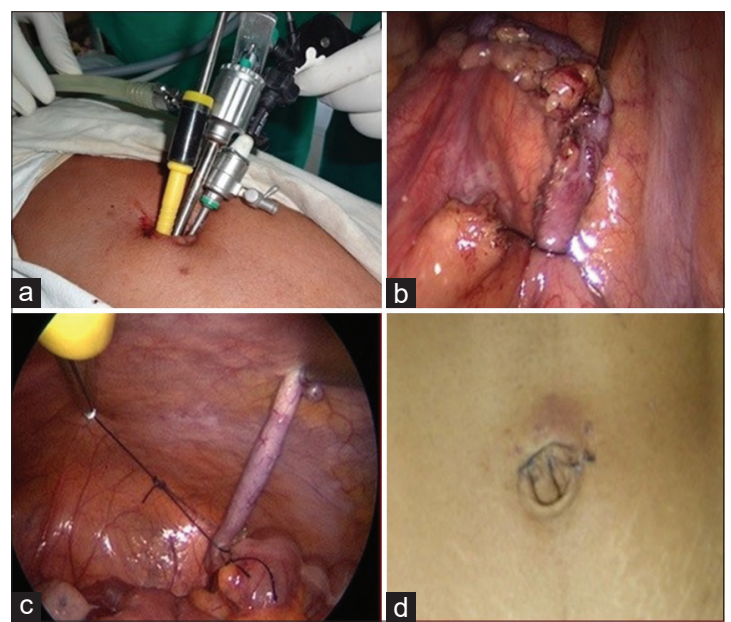

Figure 2: (a-d) Photographs showing (Clockwise from left upper corner) Two $5 \mathrm{~mm}$ and one $3 \mathrm{~mm}$ ports, Appendix with $1^{\text {st }}$ Roeders Knot, Appendix with $2^{\text {nd }}$ Roeders Knot and hardly visible post-operative scar

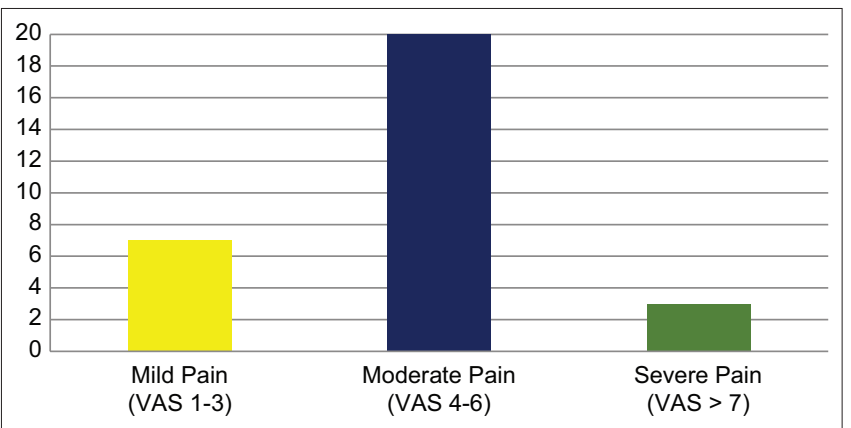

Figure 3: Severity of post-operative pain 


\begin{tabular}{|c|c|c|}
\hline Procedure details & Number of cases & Percentage \\
\hline $\begin{array}{l}\text { Completed using } 3 \text { ports in } \\
\text { single incision }\end{array}$ & 16 & 53.33 \\
\hline Additional rescue port & 6 & 20.00 \\
\hline Usage of Prolene loop & 6 & 20.00 \\
\hline $\begin{array}{l}\text { Usage of } 2 \mathrm{~mm} \text { Alligator } \\
\text { forceps }\end{array}$ & 1 & 3.33 \\
\hline Conversion to open & 1 & 3.33 \\
\hline
\end{tabular}

\begin{tabular}{lc} 
Table 4: Post-operative complications in studied \\
cases \\
\hline Post-operative complications & No of patients \\
\hline Wound Infection & 5 \\
Peritonitis & 1 \\
\hline
\end{tabular}

\begin{tabular}{lcc}
\multicolumn{3}{l}{ Table 5: Hospital stay of the patients } \\
\hline No of days & No of patients & Percentage \\
\hline 2 & 18 & 60 \\
3 & 9 & 30 \\
4 & 2 & 6.66 \\
$>4$ & 1 & 3.34 \\
\hline
\end{tabular}

Pain was measured at the end of $6 \mathrm{~h}$ post-operative time using 0-10 numerical pain rating scale (VAS score). Out of 30 cases, 7 patients $(23.33 \%)$ were found to have mild pain (VAS score 1-3) whereas moderate pain (VAS score 4-6) was seen in $20(66.66 \%)$ patients. Severe pain (VAS $>6$ ) was seen in 3 patients (10\%) (Figure 3).

\section{DISCUSSION}

In this study, 30 patients of appendicitis treated by Single Incision LA were included. IN our study there was a female preponderance with a M:F ratio of 1:6.15. Frutos et al. ${ }^{13}$ conducted a study of 73 patients with acute appendicitis treated by SILS. In this study, the authors found that None of the patients required conversion to conventional laparoscopy. The mean surgical time was $40 \pm 14$ (16-80) minutes. There were no complications during or after the surgery. The mean post-surgical pain score was $3 \pm 1(1-7)$ and the mean hospital stay was found to be $18 \pm 7(9-42)$ hours. The gender distribution of studied cases showed that there was a female preponderance with $\mathrm{M}$ : F ratio being 1:1.43. This female preponderance was similar to our study. Some other authors such as Addiss et al. ${ }^{14}$ reported a male preponderance in cases of acute appendicitis.

The mean age of studied cases in our study was found to be 26.2 years. Sonawane et al. conducted a study of 138 patients of acute appendicitis. ${ }^{15}$ The authors found that the mean age of studied cases was 27.41 years. Similarly,
Resutra et al. ${ }^{16}$ in their study of 400 patients of acute appendicitis treated by open as well as LA found the mean age of studied cases to be 35 years.

In this study, the mean operative time for 30 patients is $96.86 \mathrm{~min}$. In the first 15 cases the mean operative time was $120.00 \mathrm{~min}$ however in the next 15 cases it has come down to $73.73 \mathrm{~min}$. This has been mainly attributed to the learning curve for single-incision laparoscopic procedure range (40-175 $\mathrm{min})$. In Kim et al. ${ }^{17}$ study, the mean operative time was $61.3 \mathrm{~min}$ (range 24-120 min). In Chiu et al. ${ }^{18}$ study, the mean operative time was $58 \mathrm{~min}$ (33-107 min). The operating surgeon's experience is one of the important factors apart having a major impact on mean operative time in cases of laparoscopic surgeries.

In this study, out of 30 cases, 16 cases were completed by using 3 ports. In six cases a prolene loop was inserted with the help of epidural needle in the right iliac fossa to suspend the appendix. In one case a $2 \mathrm{~mm}$ alligator grasper was used through the suprapubic region to suspend the appendix. In 6 cases an additional $5 \mathrm{~mm} / 3 \mathrm{~mm}$ port was used during the procedure. In One case Single incision LA was converted to open appendectomy due to non-visualization of the appendix. Out of 30 cases, the procedure was completed with Single Incision LA in 23 Patients, i.e., $76.6 \%$. In a similar study by Uday et al. ${ }^{19}$ study, all 32 patients were completed with single incision laparoscopic procedure, i.e., $100 \%$. In this study, a SILS port was used in all cases.

In this study out of 30 cases, five patients had Post-Operative wound Infection. One patient had post-operative Peritonitis for which re-exploration was done on post-operative day 2 and abdominal wash was given. In a similar study by Bhatia et al. ${ }^{20}$ study, out of 17 cases, no post-operative complication reported.

\section{Limitations of the study}

Small number of cases and absence of a comparator group were limitations of this study. A well designed large comparative study would give further insights into advantages of Single incision laparoscopic appendectomy over conventional methods.

\section{CONCLUSION}

SILS is a safe procedure having excellent cosmetic results. With increasing experience, the operative time goes down and difficulties of crowding at the umbilicus can be reduced considerably using small size ports. 


\section{ACKNOWLEDGMENT}

Department of surgery Government Medical College Chandrapur Maharashtra India for extending their valuable support in undertaking this study.

\section{REFERENCES}

1. Nshuti R, Kruger $D$ and Luvhengo TE. Clinical presentation of acute appendicitis in adults at the Chris Hani Baragwanath academic hospital. Int J Emerg Med. 2014;7(1):12.

https://doi.org/10.1186/1865-1380-7-12

2. Hosseini A, Omidian $\mathrm{J}$ and Nazarzadeh R. Investigating diagnostic value of ultrasonography in acute appendicitis. Adv Biomed Res. 2018;7:113.

https://doi.org/10.4103/abr.abr_79_18

3. Mun S, Ernst RD, Chen K, Oto A, Shah S and Mileski WJ. Rapid CT diagnosis of acute appendicitis with IV contrast material. Emerg Radiol. 2006;12(3):99-102.

https://doi.org/10.1007/s10140-005-0456-6

4. Sayed AO, Zeidan NS, Fahmy DM and Ibrahim HA. Diagnostic reliability of pediatric appendicitis score, ultrasound and lowdose computed tomography scan in children with suspected acute appendicitis. Ther Clin Risk Manag. 2017;13:847-854.

https://doi.org/10.2147/tcrm.s134153

5. Gorter RR, Eker HH, Gorter-Stam MA, Abis GS, Acharya A, Ankersmit $M$, et al. Diagnosis and management of acute appendicitis. EAES consensus development conference 2015. Surg Endosc. 2016;30(11):4668-4690.

https://doi.org/10.1007/s00464-016-5245-7

6. Hori T, Machimoto T, Kadokawa $\mathrm{Y}$, Hata $\mathrm{T}$, Ito $\mathrm{T}$, Kato $\mathrm{S}$, et al. Laparoscopic appendectomy for acute appendicitis: How to discourage surgeons using inadequate therapy. World $\mathrm{J}$ Gastroenterol. 2017;23(32):5849-5859.

https://doi.org/10.3748/wjg.v23.i32.5849

7. Bonanni F, Reed J $3^{\text {rd }}$, Hartzell G, Trostle D, Boorse R, Gittleman $\mathrm{M}$ and Cole A. Laparoscopic versus conventional appendectomy. J Am Coll Surg. 1994;179(3):273-278.

8. Switzer NJ, Gill RS and Karmali S. The evolution of the appendectomy: from open to laparoscopic to single incision. Scientifica (Cairo). 2012;2012:895469.

https://doi.org/10.6064/2012/895469

9. Tsin DA, Colombero LT, Lambeck $J$ and Manolas $P$. Minilaparoscopy-assisted natural orifice surgery. JSLS.
2007;11(1):24-29.

10. Shaikh AR, Sangrasi AK and Shaikh GA. Clinical outcomes of laparoscopic versus open appendectomy. JSLS. 2009;13(4):574-580.

https://doi.org/10.4293/108680809x1258998404524

11. Kumar A, Sinha AN, Deepak D, Pandey NK and Nandani. Single incision laparoscopic assisted appendectomy: Experience of 82 cases. J Clin Diagn Res. 2016;10(5):PC01-PC03. https://doi.org/10.7860/jcdr/2016/8146.7775

12. McCaffery $M$ and Pasero $C$. $0-10$ numeric pain rating scale. In: Pain: Clinical Manual. St Louis, MO: Mosby; 1999. p. 16.

13. Frutos $M D$, Abrisqueta J, Luján JA, García $A$, Hernández $Q$, Valero G, et al. Single incision transumbilical laparoscopic appendectomy: Initial experience. Cir Esp. 2011;89(1):37-41. https://doi.org/10.1016/j.ciresp.2010.09.008

14. Addiss DG, Shaffer N, Fowler BS and Tauxe RV. The epidemiology of appendicitis and appendectomy in the United States. Am J Epidemiol. 1990;132(5):910-925 https://doi.org/10.1093/oxfordjournals.aje.a115734

15. Sonawane RS, Jatkar GL and Chaudhari MS. Correlation of ultrasonography findings of acute appendicitis with pathological acute appendicitis. Int Surg J. 2016;3(3):1447-1450. https://doi.org/10.18203/2349-2902.isj20162726

16. Resutra R, Salaria H and Gupta R. Retrospective analysis of laparoscopic versus open appendectomy for the treatment of acute appendicitis. Int Surg J. 2020;7(12):4045-4051 https://doi.org/10.18203/2349-2902.isj20205355

17. Kim HJ, Lee JI, Lee YS, Lee IK, Park JH, Lee SK, et al. Single port trans umbilicallaparoscopic appendectomy: 43 consecutive cases. Surg Endosc. 2010;24(11):2765-2769. https://doi.org/10.1007/s00464-010-1043-9

18. Chiu CG, Nguyen $\mathrm{NH}$ and Bloom SW. Single incision laparoscopic appendectomy using conventional instruments: An initial experience using novel technique. Surg Endosc. 2011;25:1153-1159. https://doi.org/10.1007/s00464-010-1332-3

19. Uday SK, Kumar $\mathrm{CH}$ and Bhargav PR. A technique of singleincision laparoscopic appendectomy using conventional multiport laparoscopic instruments (SILACI): preliminary experience of 32 cases. Indian J Surg. 2015;77(Suppl 3):764-768. https://doi.org/10.1007/s12262-013-0996-z

20. Bhatia P, Sabharwal V, Kalhan $S$ and John S. Single incision multiport laparoscopic appendectomy: How I do it. J Minim Access Surg. 2011;7(1):28-32. https://doi.org/10.4103/0972-9941.72372

\footnotetext{
Authors Contribution:

NPM- Concept and design of the study; interpreted the results, prepared first draft of manuscript and critical revision of the manuscript, Statistically analyzed and interpreted; reviewed the literature and manuscript preparation; Design of the study, statistically analyzed and interpreted, preparation of manuscript and revision of the manuscript, Concept and coordination of the overall study.

Work attributed to:

Department of Surgery, Government Medical College, Chandrapur, Maharashtra, India

Orcid ID:

Dr. Nilesh P Mangam - (1) https://orcid.org/0000-0002-7522-9198

Source of Support: Nil, Conflict of Interest: None declared.
} 